\title{
Access to emergency contraception and safe abortion services for survivors of rape: A review of policies, programmes and country experiences in sub-Saharan Africa
}

Jill Thompson

Chi-Chi Undie

Population Council

Ian Askew

Population Council

Follow this and additional works at: https://knowledgecommons.popcouncil.org/departments_sbsr-rh

Part of the Demography, Population, and Ecology Commons, Domestic and Intimate Partner Violence Commons, Family, Life Course, and Society Commons, International Public Health Commons, Maternal and Child Health Commons, and the Women's Health Commons How does access to this work benefit you? Let us know!

\section{Recommended Citation}

Thompson, Jill, Chi-Chi Undie, and lan Askew. 2014. "Access to emergency contraception and safe abortion services for survivors of rape: A review of policies, programmes and country experiences in subSaharan Africa," STEP UP Research Report. Nairobi: Population Council. 


\section{STEP SUP}

STRENGTHENING EVIDENCE FOR PROGRAMMING ON UNINTENDED
PREGNANCY

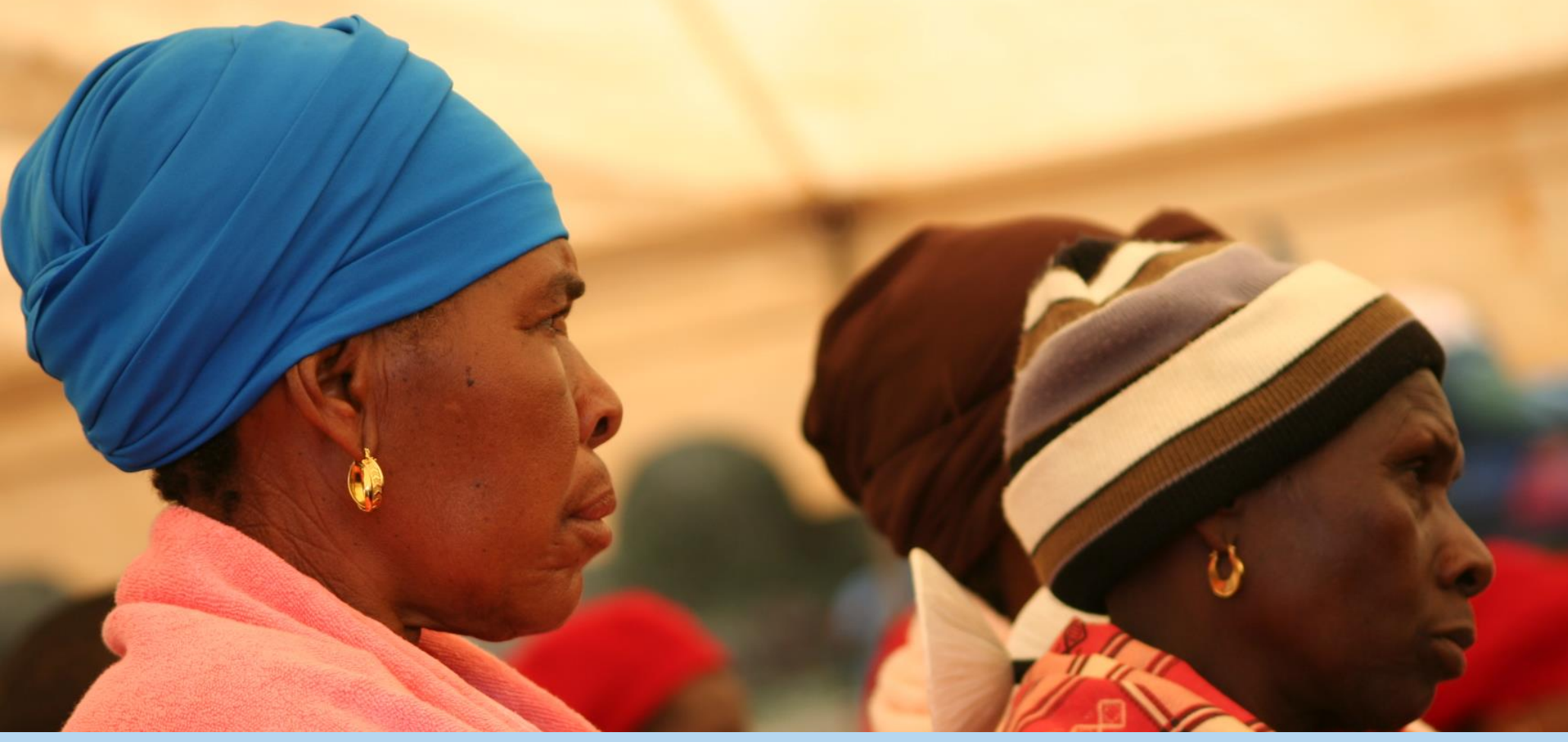

Access to Emergency Contraception and Safe Abortion Services for Survivors of Rape: A Review of Policies, Programmes and Country Experiences in Sub-Saharan Africa JILL THOMPSON, CHI-CHI UNDIE, IAN ASKEW 
Access to Emergency Contraception and Safe Abortion Services for Survivors of Rape: A Review of Policies, Programmes and Country Experiences in Sub-Saharan Africa

JILL THOMPSON, CHI-CHI UNDIE, IAN ASKEW

Population Council

STEP UP RESEARCH REPORT

September 2014 
The STEP UP (Strengthening Evidence for Programming on Unintended Pregnancy) Research Programme Consortium generates policy-relevant research to promote an evidence-based approach for improving access to family planning and safe abortion. STEP UP focuses its activities in five countries: Bangladesh, Ghana, India, Kenya, and Senegal. STEP UP is coordinated by the Population Council in partnership with the African Population and Health Research Center; icddr,b; the London School of Hygiene and Tropical Medicine; Marie Stopes International; and Partners in Population on Development. STEP UP is funded by UK aid from the UK Government. www.stepup.popcouncil.org

The Population Council's Expanding the Evidence Base on Comprehensive Care for Survivors of Sexual Violence in Sub-Saharan Africa program is funded by the Swedish-Norwegian Regional HIV and AIDS Team for Africa. The program aims to reduce the impact and incidence of sexual and gender-based violence in East and Southern Africa by strengthening the medical, legal, and justice sectors' capacities for caring for survivors of such violence. The program works to achieve this aim by testing and rigorously documenting best practices in sexual and gender-based violence service provision; providing South-South technical assistance through a network of implementing partners; and by influencing policy and programs through the dissemination of best practices to key audiences. www.popcouncil.org,

www.svri.org/popcouncil.htm

\section{POPULATION COUNCIL \\ Ideas. Evidence. Impact.}

The Population Council confronts critical health and development issues-from stopping the spread of HIV to improving reproductive health and ensuring that young people lead full and productive lives. Through biomedical, social science, and public health research in 50 countries, we work with our partners to deliver solutions that lead to more effective policies, programs, and technologies that improve lives around the world. Established in 1952 and headquartered in New York, the Council is a nongovernmental, nonprofit organisation governed by an international board of trustees.

Suggested citation: Jill Thompson, Chi-Chi Undie, lan Askew. 2014. "Access to Emergency Contraception and Safe Abortion Services for Survivors of Rape: A Review of Policies, Programmes and Country Experiences in Sub-Saharan Africa." Nairobi: Population Council.

(c) 2014 Population Council Inc.

Please address any inquiries about STEP UP to the RPC co-directors:

- Dr. Harriet Birungi, hbirungi@popcouncil.org

- Dr. lan Askew, laskew@popcouncil.org 


\section{Contents}

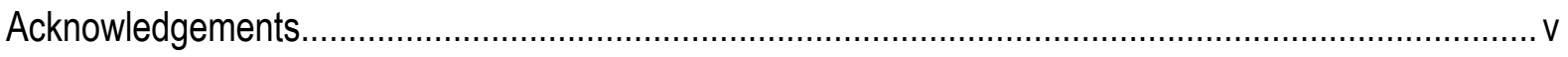

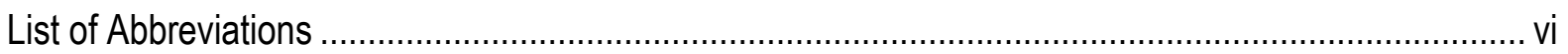

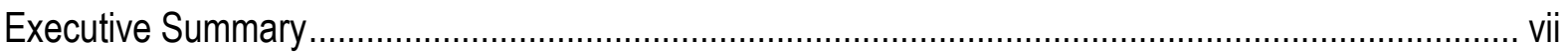

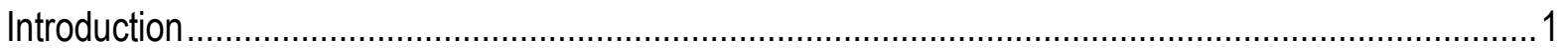

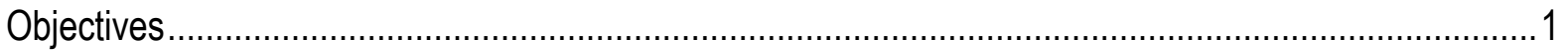

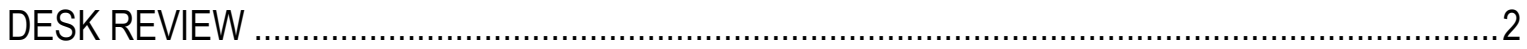

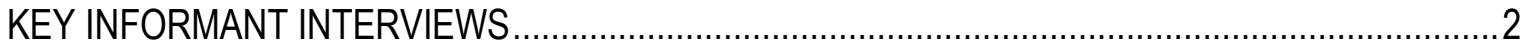

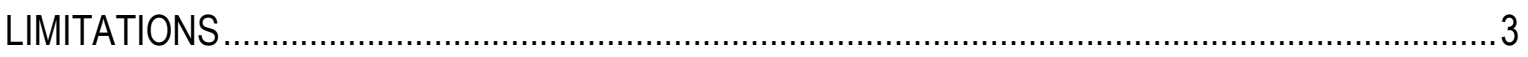

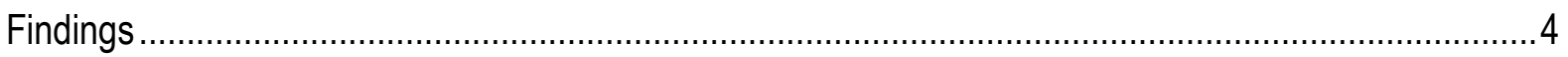

INTERNATIONAL AND REGIONAL LEGAL FRAMEWORKS ON SEXUAL VIOLENCE AND

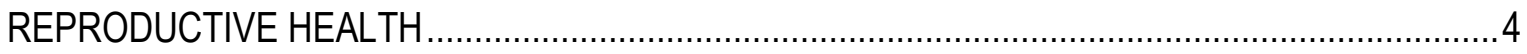

WHO Guidelines on Emergency Contraception and Safe Abortion for PRC .......................... 8

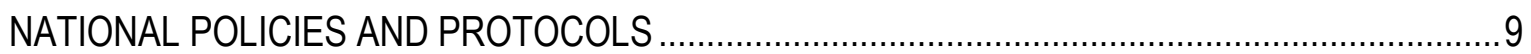

Countries with National Guidelines for Care and Management of Sexual Assault......................

Comparisons with WHO Guidance ............................................................................... 10

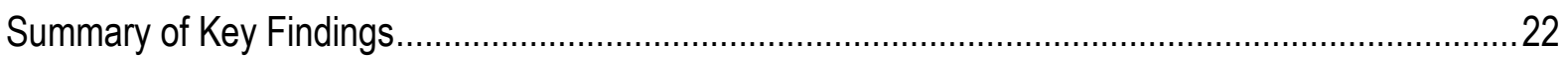

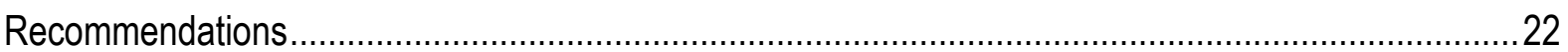

References 


\section{Acknowledgements}

Two regional programmes of the Population Council provided financial support for this study: the Strengthening Evidence for Programming on Unintended Pregnancy (STEP UP) research programme consortium (funded by the Department for International Development, with U.K. aid from the U.K. government), and the Expanding the Evidence Base on Comprehensive Care for Survivors of Sexual Violence in Sub-Saharan Africa programme (funded by the Swedish-Norwegian Regional HIV and AIDS Team for Africa).

We gratefully acknowledge the contributions of all key informants to this study, as well as the support of the following Population Council colleagues in either facilitating or conducting the data collection in various countries: Babatunde Ahonsi, Nafissatou Diop, Annabel Erulkar, Selina Esantsi, Salisu Ishaku, Gisele Kabore, Sisay Mellese, Saiqa Mullick, Placide Tapsoba, and Godwin Unumeri. Our thanks also go to our colleagues Janet Munyasya and Nancy Termini for formatting and/or reviewing the report. 


\section{List of Abbreviations}

CEDAW UN Convention on the Elimination of all forms of Discrimination Against Women

EC Emergency Contraception

ECP Emergency Contraceptive Pill

FP Family Planning

GBV Gender-Based Violence

HCP Health Care Provider

ICPD International Conference on Population and Development

IUD Intra-Uterine Device

MDG Millennium Development Goal

$\mathrm{MoH} \quad$ Ministry of Health

NGO Non-Governmental Organisation

PEP Post-Exposure Prophylaxis for HIV

PRC Post-Rape Care

$\mathrm{RH} \quad$ Reproductive Health

SA Safe Abortion

SADC Southern African Development Community

STEP UP Strengthening Evidence for Programming on Unintended Pregnancy

STI Sexually-Transmitted Infection

SV Sexual Violence

WHO World Health Organisation 


\section{Executive Summary}

This study examined how pregnancy prevention and management services (specifically, the provision of emergency contraception, pregnancy testing and counselling, and termination or referral for termination of pregnancy services) feature within post-rape care (PRC) services in sub-Saharan Africa. Guidance provided by the World Health Organisation was used as a benchmark for examining these issues. The study drew on a range of sources via a desk review, as well as on information provided through key informant interviews.

Several key messages emerge from the study's overall findings:

1. National PRC guidelines consistently identify pregnancy prevention as an essential element of sexual assault management and all include provisions on emergency contraception for eligible survivors. Nonetheless, the study reveals a disconnect between PRC guidelines and guidelines for reproductive health/family planning, with the latter less likely to address the specific needs of rape survivors although many contain general provisions on emergency contraception.

2. Pregnancy management and safe abortion for survivors do not feature prominently in national sexual violence guidelines in the region, with only a few exceptions. Existing provisions for pregnancy management and abortion also tend to lack detailed guidance or country-specific information that would facilitate access to these services. Pregnancy counseling is unevenly addressed across the national protocols examined.

3. Of the eight national protocols reviewed, only three treat safe abortion as an essential element of care to be provided for rape survivors, with clear guidance on its provision.

The existence of numerous national guidelines in the region demonstrates countries' desire to respond to this public health and legal challenge. However, if left in their current state, the gaps and inconsistencies observed across most national guidelines contribute to a violation of survivors' rights and of good medical practice as outlined in international protocols. In conclusion, countries in the Sub-Saharan Africa region would benefit from intensive support to update and consolidate guidance on these critical issues.

The recommendations arising from this study are outlined below:

- Engage regional bodies mandated to foster regional cooperation in health to communicate these findings so that they can facilitate harmonisation and adherence to regional and international standards of care for rape survivors.

- Support regional bodies to develop prototype guidance that can be adapted by countries throughout the region.

- Convene regional workshops to promote and support the updating and consolidation of national guidance by countries, including the medical sector, the judiciary and civil society to enhance alignment of health system policies with national laws and rights commitments.

- Popularise revised national protocols among health providers and the police, including integration into medical and legal training curricula, and among the general public to heighten awareness of the rights of survivors to such services. 



\section{Introduction}

The medical management of injuries, infections, pregnancy and other adverse health outcomes associated with rape ${ }^{1}$ is recognised as a basic human right and an essential public health service. Over the past decade, huge strides have been made in many sub-Saharan African countries in improving the content and delivery of services for responding to sexual violence or post-rape care (PRC). In particular, improvements have focused on the integration of post-exposure prophylaxis (PEP) for prevention of HIV and other sexually transmitted infections (STIs) with injury treatment, and on linking medical management with a criminaljustice response in addition to longer-term trauma counselling (Kilonzo et al., 2009; Kim et al., 2009).

Although there is no question that these are critical elements of PRC, many women and girls are also at risk of pregnancy through rape. Indeed, the likelihood of pregnancy following rape is much greater than that of HIV infection. A study in the U.S. (Holmes et al., 1996) found a pregnancy rate of 5 percent following rape, which is similar to that of unprotected consensual sex, whereas the estimated rate of HIV infection from a single act of vaginal intercourse is $0.0003-0.0009$ percent (Wiley, Herschkorn, \& Padian, 1989; Peterman et al., 1989; Downs \& De Vincenzi, 1996; Mastro, 1996). The risk of pregnancy from rape may be even higher in cases involving violence by intimate partners $(20 \%)$, which may reflect the outcome of repeated acts reported cumulatively, and in developing countries among younger women (15-18\%) (Mulugeta et al., 1998; McFarlane et al., 2005; Krug et al., 2002; Reza et al., 2009).

Moreover, among younger, unmarried and economically dependent women and girls who attend health services for maternity care, substantial proportions report having become pregnant through rape, thus creating a need for the health system to be able to respond adequately. For example, up to ninety percent of survivors aged 12-16 years at a maternity hospital in Lima, Peru, reported having been raped, while 95 percent of pregnancies among girls aged 15 or younger at a Costa Rican shelter were reportedly caused by incest (de Bruyn, 2003).

In Ethiopia, 18 percent of women seeking pregnancy termination at a non-government organisation (NGO) clinic reported pregnancy from rape (Dessalegn, Kumbi, \& Surur, 2008). Despite these relatively high risks of pregnancy and the potential for morbidity, mortality and severe social consequences from a rape-related pregnancy, attention to and investment in pregnancy-related services within PRC - pregnancy testing, access to emergency contraception (EC), and safe abortion (SA) - have been markedly less than for other medical management services.

\section{Objectives}

The Population Council undertook a review of policies, programmes, and country experiences relating to the prevention and management of pregnancy for survivors of sexual assault in sub-Saharan Africa. Particular emphasis was placed on access by rape survivors to EC and SA services. The objectives of the study were to examine how pregnancy prevention and management services feature within PRC services in subSaharan Africa, vis-à-vis World Health Organisation (WHO) guidance; and to make policy and programmatic recommendations for expanding access to these services.

\footnotetext{
${ }^{1}$ A distinction is made in some countries between 'rape' (unlawful sex with an adult) and 'defilement' (unlawful sex with a child). In this report, the term 'rape' is used to refer to unlawful sex with both adults and children.
} 


\section{Methods}

The study drew on a range of sources via a desk review, as well as on information provided through key informant interviews. The desk review and key informant interviews are described in further detail below.

\section{DESK REVIEW}

Countries were selected for the desk review based on their being: 1) focus countries of two Population Council regional research programmes - the Africa Regional Sexual and Gender-Based Violence Network (funded by the Swedish-Norwegian Regional HIV and AIDS Team for Africa), and the Strengthening Evidence for Programming on Unintended Pregnancy (STEP UP) research programme consortium (funded by the U.K. Department for International Development); 2) countries in the region where the Population Council has offices or currently conducts related work; and 3) countries in the process of changing their laws and policies to make EC and SA more accessible to rape survivors. A total of sixteen countries were selected for the desk review, namely: Botswana, Burkina Faso, Burundi, Ethiopia, Ghana, Kenya, Malawi, Mozambique, Nigeria, Rwanda, Senegal, South Africa, Swaziland, Tanzania, Uganda, and Zambia.

The desk review focused on relevant regional legal and policy instruments, national laws and policy documents, clinical guidelines/protocols, reports and monographs from leading reproductive health $(\mathrm{RH})$ organisations; where available and relevant, published literature was also reviewed. Copies of national laws and policy documents were obtained through online sources, Population Council national office staff, key informants, a review of national Ministry of Health $(\mathrm{MoH})$ or government websites, and an internet search using key words. Websites of leading health and development organisations and reproductive health NGOs (such as the Center for Reproductive Rights, Guttmacher Institute, Ipas, the Population Council, and the World Health Organisation) were also searched for relevant data, monographs and reports. The literature review was limited to articles available online from health databases (PubMed and the Health Reference Centre/Academic database), identified through keyword searches, and/or references cited in other documents. Document searches focused on the provision of $\mathrm{EC}$ and/or safe abortion services in the postrape context, and access to EC and safe abortion in Africa.

To determine the current law on abortion in the selected countries, available legislation for each country was reviewed, including relevant sections of the criminal law, as well as specialised statutes relating to termination of pregnancy. Findings from the legal review were triangulated with abortion law databases, qualitative responses from the key informant interviews, and information contained in national sexual violence (SV) and/or RH policies, where available.

\section{KEY INFORMANT INTERVIEWS}

Recognising that there can often be a gap between policy mandates and service delivery and access, key informant interviews were conducted in ten of the sixteen study countries (Botswana, Burkina Faso, Ethiopia, Ghana, Kenya, Mozambique, Nigeria, Rwanda, Senegal, and South Africa) to cross-check and supplement the information available from the desk review. Twenty-eight (28) key informants (2-4 per country) were identified and interviewed in person or telephonically. In a few cases, where language was a barrier, respondents were also given the option to provide brief written responses to selected questions (Mozambique, Rwanda). Respondents included seven MoH officials, 11 public health care providers (HCPs), and 10 representatives of NGOs. All informants were drawn from the gender-based violence (GBV) and/or reproductive health sectors, based on their relevant experience and availability to participate in the study. A description of the study and consent form was provided to each informant for review and signature 
prior to their participation in the study. Participants were informed that they would be identified in terms of their country and professional affiliation and not individually.

Key informant interviews were conducted by Population Council staff or by the lead investigator, using a semi-structured interview format and standardised field guide. All interviews were simultaneously handrecorded or audio-taped. The interviews were transcribed by the interviewers at the end of each interview, and translated into English where necessary. The interview transcripts where then reviewed, coded and analysed based on the topics covered by the interview field guide.

\section{LIMITATIONS}

The online search of peer-reviewed literature confirmed that published research on EC and safe abortion services in the specific context of rape care is extremely limited, particularly in relation to Africa. Accessing laws and policy documents also proved to be difficult in many countries. Although this appears to be changing, many countries in the region have not yet made copies of national laws and/or policies available on government websites, or the range of available documents is incomplete. Although mentioned in the literature, Uganda's Reproductive Health Standards and Guidelines (2006) was not available on the official $\mathrm{MoH}$ website and could not be found elsewhere online. Zambia's and Malawi's official websites do not include any GBV or reproductive health policies. South Africa's MoH website includes some RH and FP documents but not the national guidelines for sexual assault care (2004). Obtaining access to "hard copy" policy documents was often extremely difficult and time-consuming, even for colleagues living in the country concerned. Occasionally, copies of laws or key documents were found on academic or non-governmental websites (such as the United Nations) or were obtained from individual sources. In many cases, however, it was not possible to identify or access relevant policy documents and include them in the review. Findings and conclusions for the study are therefore based on a limited range of documents and may not reflect the complete picture for individual countries or the region overall.

Key informant interviews were conducted to provide qualitative data regarding practices "on the ground" in selected countries. Informants were selected based on their knowledge of the sector and availability to be interviewed within the time-frame of the study. While included to enhance understanding of the issues under study, responses are not statistically significant or generalisable for individual countries or across the region. 


\section{Findings}

\section{INTERNATIONAL AND REGIONAL LEGAL FRAMEWORKS ON SEXUAL VIOLENCE AND REPRODUCTIVE HEALTH}

Most governments in Sub-Saharan Africa have ratified legally binding international treaties and conventions that protect fundamental human rights, including the right to life, liberty and security of the person, the right to non-discrimination, the right to be free from inhuman and degrading treatment, the right to education and information, and the right to the highest attainable standard of health. ${ }^{2}$ These rights are further recognised and defined in regional treaties (African Union, 2003) and are also protected by the constitutions of many countries (e.g. United Republic of Tanzania, 1977).

Violence against women is widely recognised as a form of discrimination and a violation of human rights under international and regional legal frameworks. ${ }^{3}$ Under both international and regional human rights treaties, governments have a responsibility to protect women and girls from gender-based violence and to respond effectively when violations occur. This responsibility to respond encompasses the duty to investigate and prosecute abuses, as well as to provide survivors with necessary support and rehabilitation services. Under the UN Convention on the Elimination of all forms of Discrimination Against Women (CEDAW), for example, state responsibility to survivors includes: provision of woman-centred/survivorfriendly health services for survivors of sexual and gender-based violence; establishment and implementation of sexual violence policies, including health-care protocols and hospital procedures; training of health care workers to detect and manage the health consequences of gender-based violence; and elimination of barriers to health services, such as high fees, third-party authorisation requirements, and distance to facilities. ${ }^{4}$

At regional level, the Protocol to the African Charter on the Rights of Women in Africa commits State Parties to implement "appropriate measures to ensure the protection of every woman's right to respect for her dignity and protection of women from all forms of violence, particularly sexual and verbal violence." 5 State parties must also "establish mechanisms and accessible services for effective information, rehabilitation and reparation for survivors of violence against women," under Article 4. The Southern African Development Community (SADC) Protocol on Gender and Development (2008) specifically commits governments to provide for the "comprehensive testing, treatment and care of survivors of sexual assault" (including, but not limited to emergency contraception and PEP [SADC, 2008, p.13]), training of GBV service providers, and implementation of integrated prevention and response strategies (ibid., Articles 20-25). It also states that

\footnotetext{
2 UN General Assembly (1948). Universal Declaration of Human Rights, 10 December 1948, 217 A (III). http://www.refworld.org/docid/3ae6b3712c.html; UN General Assembly (1966). International Covenant on Civil and Political Rights, 16 December 1966, United Nations, Treaty Series, vol. 999, p. 171. http://www.refworld.org/docid/3ae6b3aa0.html (right to life, liberty and security of the person, right to privacy); Art 12., UN General Assembly (1966). International Covenant on Economic, Social and Cultural Rights, 16 December 1966, United Nations, Treaty Series, vol. 993, p. 3 (recognizing the "right of everyone to the enjoyment of the highest attainable standard of health"); UN Committee on Economic, Social and Cultural Rights (CESCR) (2000). General Comment No. 14: The Right to the Highest Attainable Standard of Health (Art. 12 of the Covenant), 11 August 2000, E/C.12/2000/4.

http://www.refworld.org/docid/4538838d0.html; The Convention on the Elimination of All Forms of Discrimination against Women (CEDAW) (1979) http://www.un.org/womenwatch/daw/cedaw/text/econvention.htm.

3The Convention on the Elimination of All Forms of Discrimination Against Women (CEDAW) (1979); African Charter on Human and Peoples' Rights; The Protocol to the African Charter on Human and Peoples' Rights on the Rights of Women in Africa (2003); SADC Protocol on Gender and Development (2008)

4 CEDAW General Recommendation 24, para 15, 21 and 31; see also CEDAW General Recommendations 12 and 19 on violence against women.

5 The Protocol to the African Charter on Human and Peoples' Rights on the Rights of Women in Africa, Article 4 (also requiring state parties to establish accessible services for rehabilitation of survivors of violence)
} 
parties shall provide accessible information on the services available to GBV survivors. Similarly, the International Conference on the Great Lakes Region (2006) Protocol on the Prevention and Suppression of Sexual Violence against Women and Children commits Member States to "establish legal and medical procedures for assisting the victims and survivors of sexual violence." 6

The right to sexual and reproductive health broadly is also recognised under international and regional human rights law. In 1994, the International Conference on Population and Development (ICPD) recognised women's rights to reproductive and sexual health based on rights already recognised in international human rights documents, including, but not limited to CEDAW. According to the ICPD Programme of Action, the concept of "reproductive rights":

"rests on the recognition of the basic right of all couples and individuals to decide freely and responsibly the number, spacing and timing of their children, to have the information and means to do so, and the right to attain the highest standard of sexual and reproductive health. It also includes the right of all to make decisions concerning reproduction free of discrimination, coercion and violence."

These rights flow from other fundamental rights, such as the right to life, liberty, and security of one's person; the right to privacy, information, and health; and the right to be free from discrimination, torture and ill-treatment (Center for Reproductive Rights, 2012).

The ICPD further recognises that to comply with their international obligations, States must not only respect the health and reproductive rights of women and girls -- they must create the legal and policy environment necessary to fulfil these rights. ${ }^{8}$ Laws and policies that deny or restrict access to reproductive health services, or that criminalise medical procedures needed only by women, are therefore highly problematic from a human rights standpoint. 9 In 1999, the UN Committee on the Elimination of Discrimination Against Women affirmed that reproductive health - including access to family planning (FP) information and services - "is a basic right" under article 12 of CEDAW. 10

At regional level, the 2003 Maputo Protocol recognises the right of African women and girls to control their fertility; to decide whether to have children, the number of children and the spacing of children; to choose any method of contraception; to be protected against sexually transmitted infections; and to have education about FP (African Union, 2003, Article 14(1)). The Protocol also acknowledges the responsibility of state parties to provide information and "adequate, affordable and accessible health services" to women, especially those in rural areas" (Art 14(2)).

6 International Conference on the Great Lakes Region (2006) Protocol on the Prevention and Suppression of Sexual Violence against Women and Children, pg. 7. See also 2011 Declaration, 5 and 11: (Member States commitment to "fast track the establishment and scale up" of comprehensive GBV "Recovery Centres" within two years).

7 International Conference on Population and Development (ICPD) Programme of Action (1994); see also WHO: Safe abortion: Technical and policy guidance for health systems (2012), Section 1.2 .

$8 \mathrm{lbid}$ (recognizing the responsibility of governments to translate international commitments into national laws and policies that promote sexual and reproductive health). See also, WHO: Using human rights for sexual and reproductive health: improving legal and regulatory frameworks, http://www.who.int/bulletin/volumes/88/7/09-063412/en/.

${ }^{9}$ See CEDAW General Recommendation No. 24 (1999), para 14. See also, CRR (2004) Briefing Paper: Governments Worldwide Put EC in Women's Hands ("Countries that limit the availability of EC needlessly jeopardise women's physical and mental health...and violate their duty agreed to in the Programme of Action of the International Conference on Population and Development to ensure "the widest achievable range of safe and effective family planning and contraceptive methods.")

10 See CEDAW General Recommendation No. 24 (1999). 
Moreover, the Protocol calls upon states to:

"protect the reproductive rights of women by authorising medical abortion in cases of sexual assault, rape, incest, and where the continued pregnancy endangers the mental and physical health of the mother or the life of the mother or the foetus" (Art 14(2)(c).

This ground-breaking provision represents the first time that an international human rights instrument has explicitly articulated a woman's right to abortion in specific cases, including rape. Once ratified, states are obligated under regional human rights law to ensure that safe and legal abortion is available and accessible on these grounds. ${ }^{11}$

As yet, there is no binding, universally-held norm in international conventions that recognises a specific human right to access EC or to terminate an unwanted pregnancy. In the past fifteen years, however, various international forums, UN treaty monitoring bodies and regional human rights bodies have increasingly applied human rights principles to the issues of contraception and abortion (WHO, 2012). Among the recommendations are that States prioritise prevention of unwanted pregnancy, ensure access to the full range of contraceptive services and methods, decriminalise abortion, and make all efforts to ensure that women do not have to undergo life-threatening clandestine abortions which jeopardise their physical and mental health (CEDAW, 1999; UN Human Rights Committee, 2000). Human rights bodies have also recommended that abortion should be legal at a minimum when continuation of the pregnancy endangers the life and health of the woman and in cases of rape and incest (CEDAW, 1999). States should also ensure timely and affordable access to good-quality reproductive health services, which should be delivered in a way that ensures a woman's informed consent, respects her dignity, guarantees her confidentiality, and is sensitive to her needs and perspectives. ${ }^{12}$

The international community has pledged commitment to reducing unsafe abortion through expanding and improving access to and quality of FP services and, where national laws allow, providing women with highquality, safe abortion care (WHO, 2012). At the five-year review of the ICPD, states were encouraged to review laws containing punitive measures against women who undergo illegal abortions (UN, 1999). Governments also agreed that, "in circumstances where abortion is not against the law, health systems should train and equip health-service providers and should take other measures to ensure that abortion services are safe and accessible" (ibid., p.17). The problems of unwanted pregnancy and unsafe abortion are also linked to the Millennium Development Goals (MDGs); MDG 5a is to reduce the maternal mortality rate and meeting this goal necessarily requires states to reduce unsafe abortions, which account for an

\footnotetext{
11 Of the sixteen countries in this study, eleven (11) have ratified the Maputo Protocol: Burkina Faso, Ghana, Malawi, Mozambique, Nigeria, Rwanda (with reservations), Senegal (with reservations), South Africa, Tanzania, Uganda, Zambia. See: http://www.africaunion.org/root/au/Documents/Treaties/List/Protocol\%200n\%20the\%20Rights\%200f\%20Women.pdf. Burundi, Kenya, Ethiopia and Swaziland have signed but not ratified the treaty.

12 For detailed summary and citations of monitoring body decisions relating to human rights and abortion, see WHO: Safe abortion: technical and policy guidance for health systems (2012), Chapter 4. See also CEDAW General Recommendation 24; Protocol to the African Charter on the Rights of Women in Africa, Art 14(2)(c).
} 
estimated $14 \%$ of maternal deaths in Africa. ${ }^{13}$ Preventing unsafe abortion is also one of the five key strategies for reducing maternal mortality endorsed by the WHO in $2004 . .^{14}$

Although reproductive health and services for survivors of sexual violence are frequently discussed in international human rights forums and documents, few have explicitly recognised a right by rape survivors to access EC or safe abortion. An exception is the SADC Protocol on Gender and Development (2008) which specifically commits governments to provide EC and PEP to survivors of sexual assault, as well as the Maputo Protocol. ${ }^{15}$ In addition, the UN Commission on the Status of Women recently issued a report affirming international commitments to end violence against women and girls and to ensure access to sexual and reproductive health services for survivors. Among the document's "agreed conclusions" is language explicitly calling for access to EC and safe abortion (where legal) for survivors of sexual violence: 16

\section{States must:}

"Address all health consequences, including the physical, mental and sexual and reproductive health consequences, of violence against women and girls by providing accessible health-care services that are responsive to trauma and include affordable, safe, effective and good-quality medicines, first line support, treatment of injuries and psychosocial and mental health support, emergency contraception, safe abortion where such services are permitted by national law, postexposure prophylaxis for HIV infection, diagnosis and treatment for sexually transmitted infections, training for medical professionals to effectively identify and treat women subjected to violence, as well as forensic examinations by appropriately trained professionals" (emphasis added).

\section{EMERGENCY CONTRACEPTION AND SAFE ABORTION IN THE INTERNATIONAL GUIDELINES FOR PRC}

Pregnancy prophylaxis through EC, along with medical-legal examination, treatment of injuries, counselling, and prophylactic treatment for HIV and STIs, is consistently identified as one of the minimum, "core" requirements for PRC, and features prominently in international standards for PRC, including in humanitarian and low resource settings. ${ }^{17}$ In addition to EC methods and regimens, most international guidelines also provide guidance on pregnancy testing, eligibility for EC, and survivor information and counselling. Because abortion is illegal or highly restricted in many countries, safe abortion does not feature prominently in the international PRC protocols. However, most guidelines - including the 2003 and most recent 2013 WHO guidelines - state that survivors who become pregnant from sexual violence should be advised of their options and referred for abortion where legally available. ${ }^{18}$

\footnotetext{
${ }^{13}$ World Health Organisation (WHO), Unsafe Abortion: Global and Regional Estimates of the Incidence of Unsafe Abortion and Associated Mortality in 2008, sixth ed., Geneva: WHO, 2011. See also, Guttmacher Institute, In Brief: Facts on Abortion in Africa, available at www.guttmacher.org/pubs/IB_AWW-Africa.pdf.

${ }^{14}$ See Reproductive health strategy to accelerate progress towards the attainment of international development goals and targets. Geneva, World Health Organisation, 2004. ("As a preventable cause of maternal mortality and morbidity, unsafe abortion must be dealt with as part of the Millennium Development Goal on improving maternal health and other international development goals and targets.")

15 For analysis on implications of Maputo Protocol, see, e.g. Ngwena, C. G. (2010).

${ }^{16}$ See Report on the 57th Session of the Commission on the Status of Women, Agreed Conclusions 22 and 34(iii), March 2013.

17 See, e.g. WHO "Guidelines for medico-legal care for survivors of sexual violence" (2003), Chapter 6 "Treatment and Follow-up Care," sections 6.2 and 6.7; Chapter 7 "Child Sexual Abuse," sections 7.7.3 and 7.8.3. "Clinical management of rape survivors: developing protocols for use with refugees and internally displaced persons. Geneva, World Health Organisation, 2004; IPPF/WHR "Improving Health Sector Response to Gender-Based Violence: A Resource Manual for Health Care Professionals in Developing Countries (2004). 18 lbid.
} 
WHO Guidelines on Emergency Contraception and Safe Abortion for PRC

WHO guidance on EC and SA in the context of PRC is provided in several key documents. These include:

- Guidelines for Medico-legal Care for Survivors of Sexual Violence (2003);

- Clinical Management of Rape Survivors: Developing Protocols for Use with Refugees and Internally Displaced Persons (2004);

- Safe Abortion: Technical and Policy Guidance for Health Systems, $2^{\text {nd }}$ Edition (2012); and

- Responding to Intimate Partner Violence and Sexual Violence Against Women: WHO Clinical and Policy Guidelines (2013).

The most recent WHO guidance (from 2013) provides several standards. These include that if a woman presents after the time required for EC ( 5 days), if EC fails, or if a woman presents with a pregnancy as a result of rape, she should be offered safe abortion in accordance with national law (Recommendation 14). WHO guidance from 2003 states that women who wish to maintain a pregnancy brought about by rape should be advised of available options for adoption or foster care. More detailed guidance on EC and SA is provided in Chapter 6 of the 2003 WHO Guidelines. This particular document outlines the standards and procedures for health providers regarding access to EC in cases of sexual assault, pregnancy testing, survivor information, counselling, referral and follow up, as well as specific dosing regimens for both progestin-only pills and combined oral contraceptives. (intra-uterine devices [IUDs] were not included in the 2003 guidelines). Pregnancy prevention and management in the case of child sexual abuse is also addressed in Chapter 7. The recommended protocol is the same for both adult women and girls of reproductive age.

WHO's management guidelines for sexual violence do not include detailed guidance or clinical standards for termination of pregnancy in the case of rape or other sexual assault. However, relevant guidance may be found in the 2012 document, Safe Abortion: Technical and Policy Guidance for Health Systems (second edition), which includes detailed clinical guidelines on abortion and recommendations for abortion-related services (i.e. methods for medical and surgical abortion, pre- and post-abortion care and counselling, facilities/equipment and training), as well as policy guidance on legal and administrative issues (WHO, 2012). With respect to rape survivors, section 3.3.5.5 of this document states the following:

"Women who are pregnant as a result of rape have a special need for sensitive treatment, and all levels of the health system should be able to offer appropriate care and support. Standards and guidelines for provision of abortion in such cases should be elaborated, and appropriate training given to health-care providers and police. Such standards should not impose unnecessary administrative or judicial procedures such as requiring women to press charges or to identify the rapist. The standards should ideally be part of comprehensive standards and guidelines for the overall management of survivors of rape, covering physical and psychological care, emergency contraception, post-exposure prophylaxis for HIV prevention, treatment for sexually transmitted infections (STIS) and injuries, collection of forensic evidence, and counselling and follow-up care" (emphasis added). 
The guidance also states that in cases of rape and incest:

"Prompt, safe abortion services should be provided on the basis of a woman's complaint rather than requiring forensic evidence or police examination. Administrative requirements should be minimised and clear protocols established for both police and health-care providers as this will facilitate referral and access to care" (emphasis added) (ibid.).

WHO's (2012) general guidance for health systems strengthening to offer safe abortion services includes:

- Safe abortion services should be readily available and affordable to all women, to the full extent of the law.

- Services should be available at primary-care level, with referral systems in place for all required higher-level care.

- Abortion care can be safely provided by any properly trained health-care provider, including midlevel (i.e. non-physician) providers.

- Medical abortion (mifepristone/misoprostol) and MVA are recommended for pregnancies of up to 14 weeks

- Training of abortion providers must ensure that they have the competencies to provide good-quality care in accordance with national standards and guidelines.

- Information counselling should be voluntary, confidential, non-directive, and provided by trained personnel

- Providers who object to abortion on conscientious grounds must refer survivors to another qualified provider

- Services should be provided as promptly as possible, without delay.

\section{NATIONAL POLICIES AND PROTOCOLS}

\section{Countries with National Guidelines for Care and Management of Sexual Assault}

Of the sixteen countries included in the study, at least ten have developed official national guidelines or protocols for management of rape and sexual assault. Most of these have been developed within the past five years:

- Botswana (2012)

- Ethiopia (2009)

- Kenya (2009) and (2013)(3d ed.)

- Malawi (2012)

- Mozambique (2012)

- Rwanda (2009)
- South Africa (2004)

- Tanzania (2012)

- Uganda (2007)

- Zambia (2010)

Eight of these guidelines were obtained and independently reviewed for this study. ${ }^{19}$

The following countries do not appear to have specific national guidelines on PRC, although elements of care may be contained in other policies: Burkina Faso, Burundi, Ghana, Nigeria, and Senegal. ${ }^{20}$

\footnotetext{
${ }^{19}$ Guidelines for Uganda and Mozambique were not obtained in time or were not available in English. However, researchers were able to confirm from key informants that emergency contraception is included in these guidelines, along with other key elements of PRC. See, e.g. Center for Reproductive Rights, Technical Guidance to Understanding the legal and policy framework on Termination of Pregnancy in Uganda (2012) at p. 38-39. Some countries with published guidelines (including South Africa, Rwanda and Kenya) are in the process of reviewing their national guidelines; the guidance documents reviewed were the most recent versions available.

20 The information received was conflicting in terms of whether Senegal has developed national guidelines for sexual assault and no official policy was located in the document search. According to the MoH informant, Senegal has a protocol for managing sexual assault that "provides for all necessary care, including counselling, medical care, psycho-social. [EC] is well integrated in this system." The ICEC fact sheet also refers to national guidelines, but states that "EC is not yet included in the national guidelines for PRC." ICEC Fact sheet
} 
As some key informants explained:

"When it comes to managing rape specifically, there is nothing that goes by that name." HCP, Burkina Faso

"I am not aware of any policy, locally or nationally [that addresses the clinical management needs of rape survivors in Nigeria.]" NGO representative, Nigeria

The document review confirmed that existing national protocols address all or most of the major elements of comprehensive clinical care (medico-legal exam, pregnancy and STI/HIV prophylaxis, treatment of injuries, counselling, referral and follow-up). A few, such as Zambia, also include multi-sectoral guidelines for integration with legal and/or social services. Tanzania's protocol includes a section on the role of health providers in establishing linkages with community stakeholders and conducting community outreach around GBV and GBV services. ${ }^{21}$

In addition to, or in lieu of national standards on PRC, many countries have national reproductive health policies, protocols or standards which contain some provisions on gender-based violence, $E C$, and/or abortion-related care. To the extent possible, these policy documents were also obtained and reviewed to determine whether - and to what extent - the provision of EC and SA services for rape survivors aligns with WHO guidance on the subject.

\section{Comparisons with WHO Guidance}

National PRC guidelines from these eight countries were analysed to determine whether and to what extent the national protocols adhere to WHO guidance for pregnancy prevention and management in the context of sexual assault. All of these countries consistently identify pregnancy prevention as an essential element of PRC. Four of the protocols state that PRC will be provided free of charge (Botswana, Kenya, South Africa and Zambia). Ethiopia's indicates that services should be offered free "if possible, for those who cannot afford them." The specific needs of rape survivors are less likely to be addressed in RH and FP policies, although many contain general provisions on EC. Provisions on pregnancy counselling and management and on safe abortion vary from country to country.

\section{Emergency Contraception}

National PRC protocols generally follow the $2003 \mathrm{WHO}$ guidelines with respect to provision of EC, although some gaps and inconsistencies were noted. Not all adhere to the current guidance, however, with respect to the type of EC and the 120 hour timeframe. This is also the case with some of the countries without national protocols. Specifically:

- All of the national protocols reviewed include pregnancy prevention through EC as an essential element of care. Relevant provisions are sometimes scattered among various subheadings, including history taking, pregnancy tests, EC provision, counselling and follow-up.

- National provisions are, for the most part, consistent with WHO guidance, but tend to be less detailed, particularly in terms of pregnancy counselling and management, and the information to be provided to the survivor when administering EC.

Feb 2012: "counting what counts: tracking access to emergency contraception." www.cecinfo.org/publications-and-resources/icecpublications. NGO and HCP key informants, however, were not aware of these guidelines: "There is a protocol integrating EC - the Reproductive Health Services Protocol - but it doesn't specifically address PRC." (Key informant interview, HCP, Senegal, June 2013). ${ }^{21}$ See Section 3, National Management Guidelines for the Health Sector Response to and Prevention of Gender-based Violence, Tanzania 2012. 
- Most of the national protocols lack detailed guidance or criteria on eligibility for $E C$, including with respect to children and adolescents. (In interviews, several HCPs raised this as a concern because they were aware of children as young as nine becoming pregnant from rape). Most of the protocols state that EC should be given only when the survivor is not already pregnant and presents within the allowable timeframe; however, a few (such as Kenya) mention other factors such as reproductive age or regular contraceptive use as eligibility criteria. Zambia and Tanzania are among the few that specifically discuss risk of pregnancy in children, and state that EC should be given to any child who has started menses and/or exhibits secondary sexual characteristics.

- The national protocols tend to list a wide range of acceptable EC options - progestin-only pills $(750,30$ or $37.5 \mathrm{mg}$ levonorgestrel), combined oral contraceptive pills with both high and low oestrogen, and the IUD - but without clearly identifying the recommended stat dose of 1.5 levonorgestrel as per the current WHO standard. ${ }^{22}$

- Kenya's 2013 guidelines most closely adhere to WHO guidelines in this regard and are countryspecific in terms of available regimens. The 2013 protocol proscribes two options for EC: 1) 1.5 levonorgestrel (two tablets) in a stat dose, using Postinor-2 or Plan B; or 2) 4 combined lower oestrogen pills (Microgynon 30 or Nordette), followed by another 4 twelve hours later.

- Other national protocols identify progestin-only pills as the preferred EC regimen, both in terms of efficacy and fewer side effects (Botswana, Ethiopia, Rwanda, Zambia), but do not specify a stat dose of 1.5 levonorgestrel. It is not clear, however, whether the preferred regimen (1.5 levonorgestrel in two tablets) is actually available in public facilities, which may account for this discrepancy.

- All of the protocols indicate that EC may be given up to 5 days/120 hours after rape, although some guidelines are clearer than others. Three - Kenya, Malawi, and South Africa - clearly state, as per WHO guidelines, that all eligible survivors reporting within 120 hours should be given EC (including ECP). Other guidelines are more ambiguous, i.e. Rwanda's indicates that pills should be taken within 48-72 hours or an IUD inserted within 5 days. Zambia, Botswana and Ethiopia's protocols state that ECP are "highly effective before 72 hours," but "can be given" or "are moderately effective" within 120 hours. Some protocols also suggest that $\mathrm{COC}$ are not effective after 72 hours, raising some question as to whether survivors should be given EC after 72 hours if POP are not available. ${ }^{23}$ Tanzania's protocol states that EC is "most effective if given within 120 hours," which could suggest that EC can still be effective after 120 hours. It is also not clear from this language that EC is most effective the sooner it is given.

- Some inconsistencies were noted between WHO guidance and the regimens prescribed in national protocols: For example:

- In five of the eight countries, the regimen for the levonorgestrel/progestin-only pill was described as two doses, twelve hours apart instead of one stat dose (Ethiopia, Kenya 2009, Malawi, South Africa, Tanzania). Kenya's 3rd edition (currently in draft) prescribes a stat dose, as does South Africa's 2013 contraception clinical guidelines.

\footnotetext{
22 The 2003 WHO guidelines identify progestin-only pills as the "preferred method for EC," but provide recommended dosing regimens for a much larger list of acceptable ECP methods. The latest guidelines clearly recommend levonorgestrel 1.5 as the best method, if available, followed by combined pills.

${ }^{23}$ Many informants identified the timeframe for EC as "within 72 hours," rather than 120 hours (Botswana, South Africa, Mozambique, Nigeria, Ghana, Burkina Faso), suggesting that practices on the ground may not reflect the latest guidance.
} 
- Six of the eight protocols include an IUD as an option, but most do not mention the risks or medical eligibility criteria for IUD. Botswana is one of the few that recommend full STI prophylaxis for survivors offered this EC option to prevent infections. ${ }^{24}$ Tanzania does not mention the IUD as an EC option, while South Africa's protocol currently recommends against the IUD following rape due to increased risk of infection.

- Only three of the protocols state that EC should be repeated in the event of vomiting (Ethiopia, Malawi, South Africa) and only three mention giving survivors an anti-emetic (Ethiopia, South Africa, Tanzania).

- Seven of the eight protocols include taking of a gynaecological history, such as last menstrual period and use of contraception, usually under "history taking" rather than pregnancy testing or prevention. Zambian national guidelines include a helpful "check-list for pre-existing pregnancy" for use in history taking and EC counselling.

- Very few of the national protocols provide guidance on the information that should be provided to survivors when prescribing EC. Only Malawi and Kenya specifically include all or most of the items recommended in the $2003 \mathrm{WHO}$ guidelines. Some protocols mention one or two key points to discuss with survivors (e.g. South Africa), while others provide no guidance on counselling and information giving (e.g. Botswana, Ethiopia, Rwanda, Tanzania, Zambia).

- Only three of the national protocols state clearly that EC should be given to survivors as soon as possible after the assault (Kenya, Rwanda, and Malawi). Only one country - Ethiopia - states that EC "should be provided in the emergency room at the time of the initial visit to increase client compliance and efficacy." Others are silent on where or when EC should be given, or list EC late in the treatment flow - i.e. after the examination, voluntary counselling and testing for HIV, etc.

- Five of the protocols (Botswana, Kenya, South Africa, Zambia and Malawi) state that PRC should be made available to survivors 24 hours a day. Kenya's 2013 protocol specifically mentions 24 hour access to EC.

- Noting the time-sensitive nature of many post-rape services, Tanzania's protocol specifically requires that EC (as well as other related health services) be available and provided to survivors at all levels of health care services, including dispensaries and community health centres, even if survivors must be referred to higher level facilities for additional care.

\section{Pregnancy Testing and Counselling}

The most recent WHO guidance does not address the issue of pregnancy counselling and management, other than to state that survivors who become pregnant from rape should be referred for SA services, where legally available. The previous 2003 guidelines, however, make clear that survivors should be advised of the risk of pregnancy and that those who become pregnant should be supported and counselled regarding the options available to them. Repeat pregnancy testing and counselling, where indicated, is advised after two weeks and at a three-month follow-up.

With a few exceptions, management of pregnancy does not feature prominently in the national guidelines. While not necessarily inconsistent with WHO guidance, national provisions tend to be stated in very general "boilerplate" terms, with little in the way of detailed guidance or country-specific information.

- All eight national protocols recommend a baseline pregnancy assessment and re-testing for pregnancy at some stage after the survivor's initial visit.

24 See also South Africa's 2013 Contraception Clinical Guidelines which include IUD under emergency contraception and discuss infection risks in cases of sexual assault. 
- The timeframe for follow-up testing varies between protocols, ranging from two weeks (per WHO guidelines) to six weeks, depending on the country and whether or not the survivor has been given PEP. Three protocols specifically state that survivors should be advised to return for pregnancy testing within two weeks of the assault, or in the event of a missed period. Four protocols mention the need to assess pregnancy status again at 3 months.

- Kenya's protocol states that a pregnancy test should be given to survivors four weeks after the assault regardless of whether the survivor received EC. Tanzania's guidelines include similar language, but give a 6 week timeframe for follow-up.

- Pregnancy-related provisions under follow-up tend to be brief and non-specific - i.e., test for pregnancy and "provide support" (Rwanda), "manage accordingly" (Ethiopia), or "inform of possibilities available" (Zambia). However, some protocols address pregnancy-related issues in more detail under counselling. For example, Kenya's protocol advises HCPs to explain the "short and long term consequences of pregnancy after rape" with pregnant survivors, and provide information on child adoption or any other available options." Likewise, Tanzania's guidelines state that HCPs should assess the survivor's physical and mental health and refer for ante-natal care and PMTCT if necessary. In Uganda, management guidelines emphasise that pregnancy is a common concern for rape survivors and that "[e]motional support and clear information are needed to ensure that they understand the choices available to them if they become pregnant." The guidelines also state that "[a]ll the options available, e.g. keeping the child, adoption and, where legal, abortion, should be discussed with the woman, regardless of the individual beliefs of the counsellors, medical staff or other persons involved, in order to enable her to make an informed decisi[on]."25

- In addition to advising pregnant women of their options, protocols from Zambia and Rwanda, for example, note the need for HCPs to support survivors who become pregnant from rape and provide follow-up care. They also highlight the vulnerability of children born from rape-induced pregnancy: "Children born as a result of sexual assault may be mistreated or even abandoned by their mothers and families. They should be monitored closely and support should be offered to the mother..." (Republic of Zambia, 2011. P.55).

Guidance on pregnancy counselling is uneven across the national protocols. Somewhat more detailed guidance is provided by Ethiopia, Uganda, Zambia and Botswana, whereas Malawi's and South Africa's national guidelines barely discuss pregnancy at all. While brief, Ethiopia's protocol includes some of the clearest guidance for HCPs (see box).

\section{Excerpt from the National Guideline for the Management of Survivors of Sexual Assault in Ethiopia}

Pregnancy: Female survivors of rape require emotional support and clear information so that they understand the options they have if they become pregnant: the following options should be clearly explained:

Ante Natal Care: The need for antenatal care if the woman decides to keep the pregnancy. A clear schedule for ante natal care and the places where such services are available has to be explained. A birth plan has to be prepared

Adoption and foster centres: providers need to do community mapping to identify adoption and foster centres in their community to help the survivor who require help.

Abortion services: if the women decide not to keep a pregnancy out of rape, she is entitled to have safe abortion services. Providers should clearly explain where the services are available or offer it, if available in their facility 
A few of the protocols specifically address late reporting, that is, how to manage survivors who present when already pregnant from the rape or too late for EC. One exception is Zambia's national guidelines, which state under 'Part B: Survivors presenting after 72 hours':

... "If the survivor is pregnant, try to ascertain if she could have become pregnant at the time of the sexual assault. If she is, or may be, pregnant as a result of the sexual assault, counsel her on the possibilities available to her."

Ethiopia's guidelines also provide that a pregnancy test should be performed at a survivor's initial visit (regardless of when that is), and the pregnancy managed accordingly:

"Pregnancy test should be routinely performed for all survivors in the reproductive age at initial evaluation... If menses is overdue in a woman who has had a regular cycle or a period has been missed do urine or serum test for HCG to confirm pregnancy and if need be do ultra-sonography to confirm pregnancy and also ascertain gestational age."

Ghana does not have national PRC guidelines, but pregnancy counselling is discussed in its national safe abortion guidelines. This document stresses the need for HCPs at all levels of the health system to provide women with "full and accurate information," as well as "emotional support and guidance." It states further that HCPs should present "all options available", "focus on the needs of client," and avoid imposing their own values when providing counselling to pregnant survivors (Republic of Ghana, 2006, p. 5). According to the Comprehensive Abortion Care policy, all levels of the health system should be able to provide pregnancy assessment, counselling and referral. This includes establishing whether the survivor is pregnant, discussing risks and options, including adoption and abortion, and referring to ante-natal care if the survivor wishes to continue the pregnancy, or to termination of pregnancy services if the pregnancy is unwanted and "legal indications apply." The guidelines also state that HCPs should be prepared to refer survivors to other services as needed, including counselling for rape and incest.

Key informants from countries with national protocols confirmed that routine pregnancy testing of rape survivors at the initial visit and at follow-up is practised at public facilities offering PRC (although this could not be verified). Countries without national protocols appear less likely to offer routine testing, and do not normally test before giving EC. Informants from Ghana, Senegal and Nigeria reported, however, that HCPs routinely take the survivor's medical history, and will offer pregnancy testing to survivors when requested or "where indicated." When the survivor has not received EC, she will normally be asked to return for pregnancy testing within a week or two, or if she misses her next menstrual period.

Some informants also expressed concern about the quality of counselling, as well as bias on the part of individual HCPs. In South Africa, for example, a respondent reported that:

"Counselling generally [in public facilities], whether it is HIV testing, post-rape, or around abortion, is shocking, and if anything, it is directive...Survivors need to know that unintended pregnancies happen and it's not their fault, and [we need] competent health workers...to provide them with warmth, love and understanding as opposed to judgment and... stigma." NGO, South Africa 


\section{Termination of Pregnancy and Referral for Safe Abortion}

WHO guidance on safe abortion for rape survivors states that:

"Women who are pregnant as a result of rape have a special need for sensitive treatment, and all levels of the health system should be able to offer appropriate care and support. Standards and guidelines for provision of abortion in such cases should be elaborated, and appropriate training given to health-care providers and police. Such standards should not impose unnecessary administrative or judicial procedures such as requiring women to press charges or to identify the rapist. The standards should ideally be part of comprehensive standards and guidelines for the overall management of survivors of rape" (emphasis added) (WHO, 2012, p.69).

The guidelines also state that if the survivor becomes pregnant and wishes to terminate her pregnancy, "she should be referred to legal, safe abortion services." In order to do this, HCPs should understand what the law is in their country with respect to abortion in the case of rape so that they can explain it to the survivor or her caregivers. They also need to know where and how to refer survivors for abortion if available. Ethiopia's technical guidelines include the following language:

Health workers involved in the care of women should be well aware of the provisions of this guideline, which is an official interpretation of the law on safe abortion services as outlined below. Knowledge of the law is essential so that providers not only know what is expected of them but can also inform and educate women and the community at large (Republic of Ethiopia, 2006, p. 8).

Of the eight protocols reviewed, only Ethiopia treats SA as an essential element of care to be provided for rape survivors. This approach is reflected in the introductory language of the protocol and in the guidance for abortion in the protocol itself. Whereas other protocols are silent on abortion, or mention it rather vaguely, Ethiopia's guidelines are clear on the legal right of survivors to obtain abortions if they choose to do so, and the responsibility of HCPs to counsel and refer. Although not included in the PRC guidelines, Ethiopia has also developed Technical and Procedural Guidelines for Safe Abortion Services (2006) which includes a detailed summary of the relevant legal provisions and procedures, including the right to abortion in cases of pregnancy from rape, defilement or incest. In countries such as Tanzania or Malawi, where statutes prohibit abortion except to save the life of the mother, abortion is not mentioned at all in the national guidelines, even in terms of post-abortion care.

Other protocols mention safe abortion, but do not provide clear guidance on the law or procedures for accessing abortion in the case of rape or incest. For example, the protocols of both Zambia and Botswana state that "all the options available, e.g. keeping the child, adoption, and where legal, abortion, should be discussed with the woman in order to enable her to make an informed decision" (emphasis added). Uganda's national guidelines contain similar language, as well as a provision specifying that termination of pregnancy services for survivors may be provided by a midwife, nurse, clinical officer, medical officer, or gynaecologist/surgeon. These provisions suggest that termination of pregnancy is a legal option for survivors of rape, but the law/policy is not definitive. Zambia's protocol further states that "safe abortion services should be made available to GBV survivors," while Botswana encourages HCPs to "determine where safe abortion services are available, so you can refer survivors to this service within the law, if they so choose." While the language of these provisions suggests that abortion is legally available to rape survivors, neither protocol clearly states what the law allows or requires within the country. Neither provides information on where abortions may be obtained, time limits for obtaining abortion, or the procedures survivors must follow to access this service. 
In sum, these protocols provide health providers with very little information to effectively counsel survivors and their caregivers on their rights and options. It also increases the risk of HCPs providing incorrect or misleading information. Informants in Botswana, for example, stated that as a practical matter, survivors who are not tested for pregnancy immediately after the incident or who are sexually active are usually denied abortion if they do become pregnant as they are not able to "prove" that they are pregnant from the rape.

Kenya's provisions on abortion for rape survivors are also unclear. The 2009 version of the PRC protocol states that survivors should be given information on adoption or on termination of pregnancy as available options, but does not discuss referrals for abortion services or state whether abortions are available in public facilities for rape survivors. Section 7.2 of the protocol states that termination of pregnancy "is allowed in Kenya after rape" under the Sexual Offences Act, with psychiatric evaluation and recommendation, but this provision could not be found in the statute or confirmed by informants. Key informants reported that abortion was not allowed for rape, except where the mother's life was at risk. The 2013 version of the guidelines omits this language and instead refers HCPs and survivors to the new Constitutional provision, without stating clearly whether abortion is legally available to survivors on the basis of rape or other circumstances, or how survivors may access abortion services. It is also unclear on the responsibility of HCPs treating survivors to refer for SA if requested or the availability of SA services in public facilities. The guidelines state only that "health care providers and the survivor should be aware of the Constitutional provision about abortion," which expands the permissible grounds for abortion in Kenya to include the "health" of the mother.

South Africa's guidelines contain little information on termination of pregnancy or pregnancy counselling, but the guidance (and the law) is more straightforward. "If pregnancy results despite pregnancy prevention, counselling on termination of pregnancy should be offered (Republic of South Africa, 2004, p. 25)." Under Section 14 on "Referral", the guidelines state that survivors should be given information about "other available services" (including Reproductive Health Services/Termination of Pregnancy), and "written referrals upon request." The protocol does not state that termination of pregnancy is legally available on request in South Africa, but this information appears to be widely known in South Africa. A written referral is necessary to obtain abortion services from public facilities in South Africa.

Rwanda's national guidelines do not mention abortion, as abortion was not legally available when the guidelines were drafted. According to informants, the Ministry of Health is currently reviewing the guidelines and is planning to update them based on the provisions of the new law.

Although Ghana does not have national PRC guidelines, the national policy on comprehensive abortion care does provide some specific guidelines for abortion in cases of rape, defilement/statutory rape, and incest, as well as general guidelines for all cases in which abortion is legally available.

Whether the availability of SA services in public facilities is mentioned depends on factors such as the legal status of abortion in the country, whether the country has guidelines which include safe abortion, and to varying degrees, the personal views of the HCPs. Informants from Ghana, Ethiopia, and South Africa were most likely to report that pregnant survivors would be routinely informed about SA services. Most informants reported that SA was not included in post-rape counselling, and/or that if it were discussed as an option this would be done informally and would be at the discretion of the HCP. Others were unsure of the practice on the ground, or felt that abortion would be discussed as an option only if the survivor requested this information or insisted on termination. 


\section{Legal or Administrative Restrictions on Safe Abortion}

Although nearly half of the countries in the study allow abortion for one or more reasons, additional provisions which limit access to abortion are sometimes contained in the abortion statutes or other laws. Examples include statutory time limits, parental consent requirements for minors, and, in cases of rape and incest, a requirement for third party authorisation - such as a court order or agreement by one or more doctors - to perform the procedure. In Burkina Faso, for example, informants reported that rape survivors must obtain permission from the state prosecutor in order to obtain a legal abortion. ${ }^{26}$ Rwanda's new law requires a court order (Republic of Rwanda, 2012, p. 211). Requests for termination of pregnancy on physical or mental health grounds generally require certification by at least one doctor in addition to the HCP performing the procedure (Burkina Faso, Botswana, Rwanda, and Zambia). At present, most of the national protocols do not explain these requirements or provide guidelines for obtaining necessary approvals.

The permissible timeframe for abortion following rape varies among countries. Some statutorily limit legal abortion to the first trimester or less (10-14 weeks), whereas others provide extended timeframes in cases of rape (up to 16 weeks in Botswana, 20 weeks in South Africa) or when the pregnancy threatens the woman's health. In some cases, the statute is silent and the timeframe is determined instead by policy or medical protocols (e.g. Ghana, Ethiopia and Mozambique). In Ethiopia, for example, it appears that safe abortion may be provided by certain facilities up to 28 weeks.

In most countries in the region, minors (under 18 years) are normally required to obtain consent from a parent or guardian for medical procedures, which would include legal abortion. South Africa has lifted this restriction and requires parental consent only for minors under the age of 12 years, which allows adolescents to access SA services without needing permission from parents. Two other countries have also taken steps to make SA more accessible for minors. In Ethiopia, the national policy states that minors are not required to provide consent to obtain abortion (Republic of Ethiopia, 2006). In Ghana, it appears that any trusted adult (acting "in loco parentis") may provide consent for a minor in the case of abortion; he/she does not have to be parent/guardian (Republic of Ghana, 2006). For the other five countries, it appears that normal informed consent requirements apply to SA services.

\section{Procedures for Obtaining SA Services following Rape}

WHO guidance on provision of SA services state that:

Prompt, safe abortion services [for rape survivors] should be provided on the basis of a woman's complaint rather than requiring forensic evidence or police examination. Administrative requirements should be minimised and clear protocols established for both police and health-care providers as this will facilitate referral and access to care (WHO, 2012, p. 93).

The lack of official policy or procedures in countries where abortion for rape and incest is allowed, results in countries with similar legal provisions (such as Ghana and Botswana) interpreting and implementing them differently. The statutes in both countries state that abortion is permitted where "pregnancy is the result of rape or incest." In Ghana, there is an official MoH policy interpreting this provision which states that "the

\footnotetext{
${ }^{26}$ Note conflict between two provisions, Art 21 and Penal Code. Art 21 says abortion should be available "on request of the woman" where pregnancy results from rape or incest, whereas Penal Code says the prosecutor must determine whether an abortion is permissible, based the "materiality of the [survivor's] distress." HCP informants also reported that permission from the prosecutor is required in cases of rape.
} 
request of a rape or incest survivor is sufficient to obtain an abortion," and that all survivors under 16 are automatically entitled to legal abortion based on statutory rape laws. ${ }^{27}$

In Botswana, however, there appear to be no written policies or procedures. As a result, some hospitals and HCPs impose a high burden of proof on the survivor and require lengthy and complicated procedures to obtain approval (see details below). Young children appear to be somewhat more likely to obtain an SA than adult and adolescent survivors, but informants reported that some of the "gatekeepers" - police, social workers, HCPs, hospital management - do not allow abortion if the survivor is sexually active or if she reported late. Others seem to be misinformed about the law, believing that abortion is only available in cases of rape, not incest or defilement. According to an NGO informant, male police officers in her area were "adamant" in discussions that termination of pregnancy services are available only if the case is deemed a "rape" in the reporting documentation.

"If the case is stated as defilement or incest, some police officers said you cannot terminate the pregnancy...In their opinion, only rape is rape -- defilement and incest are treated differently" (NGO, Botswana).

These differing approaches result in safe abortion being far more accessible to rape survivors in Ghana than Botswana.

"It is a long process, with many steps. The survivor and the family need to be quite committed, otherwise they will not get the approval in time and will miss the time limit of sixteen weeks. Plus, those that don't report early have no option, no proof. The hospital won't approve [the abortion] without a police report and [negative baseline] pregnancy test... In four years I have only had two cases where I was able to get termination of pregnancy" (NGO, Botswana).

In Botswana, survivors seeking abortion usually have to prove to the satisfaction of the hospital not only that they have been raped, but that the pregnancy was caused by the rape. This position is based on the statute (Sect 160 of the Penal Code) which states:

(2) Notwithstanding the provisions of subsection (1), it shall not be an offence under this section if a pregnancy is terminated or an abortion is caused within the first 16 weeks of pregnancy, in the following circumstances and under the following conditions -

(a) where the medical practitioner carrying out the operation is satisfied, by acceptable evidence, that the pregnancy is the result of rape, defilement or incest...

The statute does not define "acceptable evidence" and Botswana does not appear to have any official guidelines interpreting what this entails. However, $\mathrm{MoH}$ and NGO informants reported that survivors in Botswana must often undergo a "lengthy," "difficult," "multi-step procedure" to meet this burden of proof. At a minimum, this includes reporting to police and undergoing medical examination, so that the HCP authorising or performing the abortion "is covered" under the law (Key informant interview, HCP Botswana, June 2013). Other informants reported that survivors must have reported soon after the assault, taken a baseline pregnancy test (that came out negative), and must not be sexually active. If they meet these criteria, they will normally be referred to a social worker or NGO who will assist them to motivate for the abortion and obtain the necessary endorsements from additional officials (i.e. police, prosecutor, $\mathrm{MoH}$ ). Then they must

\footnotetext{
27 See Republic of Ghana (2006).Prevention and Management of Unsafe Abortion: Comprehensive Abortion Care Services, Standards and Protocols p. 4: "[P]roviders should recognise that pregnancy in a minor under 16 years is the result of statutory rape. Such survivors are entitled to services as provided by law."
} 
request the hospital superintendent (in writing) to convene a medical board, obtain approval from the panel, and complete all of this before the deadline of 16 weeks. As explained by the $\mathrm{MoH}$ respondent:

"[To obtain a legal abortion], the survivor must be evaluated and the procedure approved by two doctors who agree that the pregnancy is a result of rape or defilement and a medical termination can be done. The decision is made by the hospital...First of all, there should be a police report showing that the rape occurred at a certain time when it would have been possible for the woman to have become pregnant; Also that she tested negative for pregnancy when she reported and was not given EC...If she did not report right away and was not tested for pregnancy, they could argue that she was already pregnant...It is a difficult case to prove even if [the survivor] reported because she might have become pregnant before or after if she was sexually active... They have to rule out all the other possibilities. They are worried about people abusing the system." [MoH, Botswana]

In countries where survivors must be able to "prove" that their pregnancy resulted from rape (e.g. Rwanda, Burkina Faso, and Kenya), the language of the abortion laws, and their strict interpretation, can place HCPs in a difficult position, particularly with respect to survivors who do not report or who report late:

"The law says that exemption from criminal liability for abortion in the case of pregnancy as a result of rape shall be permitted only if the woman who seeks abortion submits to the doctor an order issued by the competent court recognising one of these cases, or when [rape or incest] is proven to the Court by a person charged of abortion. The law is very new and it is still questionable -- what is required to prove to the court that the pregnancy was a result of rape? What acceptable proof can a person give to the court without a medical examination or the report to police?" [HCP, Rwanda]

Likewise, confusing and conflicting information was provided regarding the law and procedure for obtaining a safe abortion following rape in Kenya. On one hand, all of the key informants interviewed insisted that abortion was not available in Kenya for rape survivors:

"Safe abortion is only legal in Kenya if the service provider sees it as necessary for saving the life of the mother. It's allowed when the mother's life is in danger, when you as a health provider have proved beyond a reasonable doubt that by doing an abortion you are actually saving the mother's life. Then it is allowed." [HCP, Kenya]28

When pressed, however, some admitted that there was a procedure for such cases, but it was so lengthy and complicated that survivors were rarely successful in accessing the service:

"Actually there have not been any [abortions approved for rape survivors]. There are so many things to be looked into. They have to prove to somebody that it was as a result of rape and it's a long legal process... The process will determine whether [the survivor] came within the stipulated period of 72 hours? Did they get EC? Did it fail and now she has become pregnant? After that they have to go to the police. Then they have to come back [to the hospital]. The gynaecologists and psychologists will sit down as a panel on that. So it's a very long process which has not been working very well with us. Because in the process, the survivor tires and never comes back again." [Service provider, Kenya]

In Burkina Faso, the legal framework on abortion includes at least two laws with conflicting provisions Article 21 of the reproductive health law, and the Penal Code - yet there does not appear to be any $\mathrm{MoH}$ policy on the subject. Two HCPs and an MoH official interviewed were aware only of the more restrictive

\footnotetext{
${ }^{28}$ But, see Kenya's 2009 national PRC guidelines which state: "If [survivors] present with a pregnancy, which they feel is as a consequence of the rape, they should be informed that in Kenya, termination of pregnancy may be allowed after rape (Sexual Offences Act, 2006). If the woman decides to opt for termination, she should be treated with compassion, and referred appropriately." Medical Management, Section 8.
} 
requirements of the penal code provision, which requires permission from the state prosecutor to obtain legal abortion in cases of rape or incest. Aside from this requirement, none of these key informants were clear on the procedure for obtaining legal abortion in their country, or had any experience referring or receiving a rape survivor for SA services.

Only three countries in this study - Ethiopia, Ghana, and South Africa - report that abortion is available to rape survivors based on the survivor's statement and request to a health care provider, with no further "evidence" or approval required. In Ethiopia, this policy is contained in the law itself. According to Article 551 of Ethiopia's criminal code, for example:

(2) In the case of terminating pregnancy in accordance with subarticle (1) (a) of Article 551 the mere statement by the woman is adequate to prove that her pregnancy is the result of rape or incest.

The fact of a minor's pregnancy is sufficient to qualify for abortion under the law, either as "statutory rape" or based on age alone. The survivor need not have reported to police or identified the perpetrator in order to receive legal abortion services. Indeed, Ethiopia's national guidelines explicitly protect HCPs from criminal liability, where abortion services are provided in good faith, based on the survivor's complaint:

"The service provider shall not be prosecuted if the information provided by the woman is subsequently found to be incorrect" (Republic of Ethiopia, 2006, p.11).

This policy is reiterated in Ethiopia's policy documents and guidelines, ${ }^{29}$ and was confirmed by key informants:

"There is not any procedure or steps required to undergo safe abortion if the [legal] conditions are fulfilled. In the case of rape, if a woman or girl says that pregnancy is the result of rape, she has a full right to get access to abortion services without any additional evidence." [NGO, Ethiopia]

"[There are] no steps, no procedures. Just her words are enough." [HCP, Ethiopia]

In South Africa, abortion is available "upon request," for any reason, within the first twelve weeks of the pregnancy (Choice on Termination of Pregnancy Act of 1996 (as amended 2008), Sect (2)(1)(a-b)). After that, a medical practitioner may terminate the pregnancy if, after consultation with the pregnant woman, he/she is "of the opinion...that the pregnancy resulted from rape or incest," or, alternatively, that the continuation of the pregnancy would pose a risk to the woman's physical or mental health. The law does not provide further guidance, but according to a key informant:

"All eligible rape survivors can access [termination of pregnancy] services after an informed consent for up to 20 weeks. Survivors can still have access to these services without opening a rape case with the police." [HCP, South Africa]

In Ghana, the statute is less clear, but the relevant MoH policy states that: In the case of sexual violence, "legal evidence of defilement, rape or incest is not required in order for the client to obtain abortion." It also states that: "providers should recognise that pregnancy in a minor under 16 years is the result of statutory rape. Such survivors are entitled to services as provided by law" (Republic of Ghana, 2006, pp. 3-4). ${ }^{29}$ See, Republic of Ethiopia (2006). Technical and Procedural Guidelines for Safe Abortion Services in Ethiopia ,, Implementation guide
for Article 551 sub-article 1A. 
According to two key informants, it is not necessary for a survivor to report rape or undergo medical examination to obtain abortion:

"In Ghana, we have what we call comprehensive abortion centres; for these centres, you don't have to show a police certification, you don't have to go to court. Whether you are raped or not, if you are carrying an unplanned pregnancy, you only need to go to the facility and complain to the doctor and then they would take you through counselling" [HCP, Ghana].

It is not clear, however, whether awareness of this policy is high in Ghana, or whether it is consistently applied in practice. An NGO informant, for example, reported:

"If you are going for an abortion because you have been raped, there is a need to prove rape ...you need to substantiate that the rape has taken place." [NGO, Ghana] 


\section{Summary of Key Findings}

This study examined how pregnancy prevention and management services (specifically, the provision of emergency contraception, pregnancy testing and counselling, and termination or referral for termination of pregnancy services) feature within PRC services in sub-Saharan Africa. Guidance provided by the World Health Organisation was used as a benchmark for examining these issues. Several key messages emerge from the study's overall findings:

1. National PRC guidelines consistently identify pregnancy prevention as an essential element of sexual assault management and all include provisions on emergency contraception for eligible survivors. Nonetheless, the study reveals a disconnect between PRC guidelines and guidelines for RH/FP, with the latter less likely to address the specific needs of rape survivors although many contain general provisions on emergency contraception.

2. Pregnancy management and safe abortion for survivors do not feature prominently in national sexual violence guidelines in the region, with only a few exceptions. Existing provisions for pregnancy management and abortion also tend to lack detailed guidance or country-specific information that would facilitate access to these services. Pregnancy counseling is unevenly addressed across the national protocols examined.

3. Of the eight national protocols reviewed, only three treat safe abortion as an essential element of care to be provided for rape survivors, with clear guidance on its provision.

The existence of numerous national guidelines in the region demonstrates countries' desire to respond to this public health and legal challenge. However, if left in their current state, the gaps and inconsistencies observed across most national guidelines contribute to a violation of survivors' rights and of good medical practice as outlined in international protocols. In conclusion, countries in the Sub-Saharan Africa region would benefit from intensive support to update and consolidate guidance on these critical issues.

\section{Recommendations}

- Engage regional bodies mandated to foster regional cooperation in health to communicate these findings so that they can facilitate harmonisation and adherence to regional and international standards of care for rape survivors. Regional bodies mandated to foster cooperation between countries should review these national variations and facilitate harmonisation among countries so that care for rape survivors in all member states adheres to regional and international standards.

- Regional bodies should develop prototype guidance documents for quality care standards that can be adapted by the medical and social services sectors, the judiciary and civil society in countries throughout the region..

- Revised national care protocols should be widely popularised among health and social services providers and the police, including integration into medical and legal training curricula, and among the general public, to heighten awareness of the rights of survivors to such services. 


\section{References}

African Union (2003). Protocol to the African charter on human and people's rights on the rights of women in Africa. http://www.refworld.org/docid/3f4b139d4.html.

CEDAW (UN Committee on the Elimination of Discrimination Against Women) (1999). CEDAW General Recommendation no. 24: Article 12 of the Convention (Women and Health), 1999, A/54/38/Rev. 1, chap. I. http://www.refworld.org/docid/453882a73.html.

Center for Reproductive Rights (2012). Briefing paper: A technical guide to understanding the legal and policy framework on termination of pregnancy in mainland Tanzania. New York: Center for Reproductive Rights. http://reproductiverights.org/sites/crr.civicactions.net/files/documents/crr_TZ_Briefing_Paper.PDF.

Choice of termination of pregnancy act of 1996, 92.

http://www.capetown.gov.za/en/CityHealth/Documentation/Documents/Act Choice on Termination of Pregnan cy_Act_92_of_1996.pdf.

de Bruyn, M. (2003). Violence, pregnancy and abortion: Issues of women's rights and public health, 2nd edition. Chapel Hill, N.C.: Ipas.

Dessalegn, S., Kumbi, S., \& Surur, F. (2008). Sexual violence and use of contraception among women with unwanted pregnancy in an NGO Clinic, Addis Ababa. Ethiopian Medical Journal 46(4):325-33.

Downs, M.A. \& De Vincenzi, I. (1996). Probability of heterosexual transmission of HIV: Relationship to the number of unprotected sexual contacts. Journal of Acquired Immune Deficiency Syndromes and Human Retrovirology 11:388-95.

Holmes, M.M., Resnick, H.S., Kilpatrick, D.G., \& Best, C.L. (1996). Rape-related pregnancy: Estimates and descriptive characteristics from a national sample of women. American Journal of Obstetrics and Gynecology 175(2):320-4.

Kilonzo, N., Theobald, S.J., Nyamato, E., Ajema, C., Muchela, H., Kibaru, J., Rogena, E, \& Taegtmeyer, M. (2009). Delivering PRC services: Kenya's experiences in developing integrated services. Bulletin of the World Health Organisation 87:555-559. http://www.who.int/bulletin/volumes/87/7/08-052340/en/.

Kim, J.C., Askew, I., Muvhango, L., Dwane, N., Abramsky, T., Jan, S., Ntlemo, E., Chege, J., \& Watts, C.al. (2009). Comprehensive care and HIV prophylaxis after sexual assault in rural South Africa: the Refentse intervention study. British Medical Journal 338:b515.

Krug, E.G., Dahlberg, L.L., Mercy, J.A., Zwi, A.B., \& Lozano, R. (2002). (eds.) World report on violence and health. Geneva: WHO. http://whqlibdoc.who.int/hq/2002/9241545615.pdf.

Mastro, T.D. (1996). Probabilities of sexual HIV-1 transmission. AIDS 10(suppl A):S75-82.

McFarlane, J., Malecha, A., Watson, K., Gist, J., Batten, E., Hall, I, \& Smith, S. (2005). Intimate partner sexual assault against women: Frequency, health consequences, and treatment outcomes. Obstetrics and Gynecology 105(1): 99-108.

Mulugeta, E., Kassaye, M., Berhane, Y. (1998). Prevalence and outcomes of sexual violence among high school students. Ethiopian Medical Journal 36(3):167-174. 
Ngwena, C. G. (2010). Protocol to the African Charter on the Rights of Women: Implications for access to abortion at the regional level. International Journal of Gynecology and Obstetrics (110): 163-166.

Peterman, T.A., Stoneburner, R.L., Allen, J.R., Jaffe, H.W., \& Curran, J.W. (1989). Risk of human immunodeficiency virus transmission from heterosexual adults with transfusion-associated infections. Journal of the American Medical Association 259:55-8.

Republic of Botswana (2004). Policy guidelines and service standards: Sexual and Reproductive Health Republic of Ethiopia (2009). National guideline for the management of survivors of sexual assault in Ethiopia. Addis Ababa: Ministry of Health. Gaborone: Family Health Division, Ministry of Health.

Republic of Ethiopia (2006). Technical and procedural guidelines for safe abortion services in Ethiopia. Addis Ababa: Family Health Department.

Republic of Ghana (2006). Prevention and management of unsafe abortion: Comprehensive abortion care services - Standards and protocols.

Republic of Rwanda (2012). Organic Law N 01/2012/OL of 02/05/2012, Organic law instituting the penal code, Official Gazette, special issue, June 14, 2012.

Republic of South Africa (2004). National management guidelines for sexual assault care. Pretoria: Department of Health.

Republic of Zambia (2011). National guidelines for the multidisciplinary management of survivors of sexual and gender-based violence in Zambia. Lusaka: Gender in Development Division.

Reza, A., Breiding, M.J., Gulaid, J., Mercy, J.A., Blanton, C., Mthethwa, Z., Bamrah, S., Dahlberg, L.L., \& Anderson, M. (2009). Sexual violence and its health consequences for female children in Swaziland: A cluster survey study. The Lancet. 373 (9679):1966-1972.

SADC (Southern African Development Community) (2008). SADC Protocol on Gender and Development. file:///C:/Users/cundie/Downloads/02392_signed_sadc_protocol_august_2008.pdf.

UN (1999). General Assembly, $21^{\text {st }}$ Special Session: Key actions for the further implementation of the Programme of Action of the International Conference on Population and Development. http://www.unfpa.org/webdav/site/global/shared/documents/publications/1999/key_actions_en.pdf.

UN Human Rights Committee (2000). CCPR General Comment No. 28: Article 3 (The Equality of Rights Between Men and Women), 29 March 2000, CCPR/C/21/Rev. 1/Add, 10.

http://www.refworld.org/docid/45139c9b4.html.

United Republic of Tanzania (1977). Constitution of the United Republic of Tanzania (last amended 1985), 26 April 1977. http://www.refworld.org/docid/3ae6b50c4.html.

WHO (2012). Safe abortion: Technical and policy guidance for health systems. $2^{\text {nd }}$ edition. Geneva: WHO.

Wiley, J.A., Herschkorn, S.J., Padian, N.S. (1989). Heterogeneity in the probability of HIV transmission per sexual contact: the case of male-to-female transmission in penile-vaginal intercourse. Statistics in Medicine 8:93102. 


\section{https://stepup.popcouncil.org}

The STEP UP (Strengthening Evidence for Programming on Unintended Pregnancy) Research Programme Consortium generates policy-relevant research to promote an evidence-based approach for improving access to family planning and safe abortion. STEP UP focuses its activities in five countries: Bangladesh, Ghana, India, Kenya, and Senegal.

STEP UP is coordinated by the Population Council in partnership with the African Population and Health Research Center; icddr,b; the London School of Hygiene and Tropical Medicine; Marie Stopes International; and Partners in Population and Development. STEP UP is funded by UK aid from the UK Government. 